\title{
Genital herpes in Canada: Deciphering the hidden epidemic
}

\author{
Mubeen Aslam MD PhD ${ }^{1}$, Rhonda Y Kropp BScN MPH${ }^{2}$, Gayatri Jayaraman MPH PhD ${ }^{1,2}$, Katherine Dinner MSc ${ }^{2}$, \\ Thomas Wong MD MPH FRCPC $2,3,4$, Marc Steben MD $^{5}$
}

\begin{abstract}
M Aslam, RY Kropp, G Jayaraman, K Dinner, T Wong, M Steben. Genital herpes in Canada: Deciphering the hidden epidemic. Can J Infect Dis Med Microbiol 2012;23(1):e6-e9.
\end{abstract}

INTRODUCTION: Genital herpes (GH) is the most common cause of genital ulceration, but is not reportable in Canada. Research in the United States has found that less than $10 \%$ of seropositive persons reported a diagnosis of $\mathrm{GH}$. The present article investigates the rates of diagnosed cases of GH in Canada from 2002 to 2007.

METHODS: Primary case diagnosis data on GH for the period between 2002 and 2007 were obtained from the Canadian Disease and Therapeutic Index, a proprietary database maintained by Intercontinental Medical Statistics (IMS) Health Canada. Of the 45,000 to 49,000 office-based physicians in Canada, IMS Health collected diagnosis-specific prescription diaries from a sample of 652 , stratified according to geographic region and representing all major specialties, during this period.

RESULTS: Between 2002 and 2007, there were approximately 84,398 to 122,456 medically attended GH cases annually in Canada. Approximately $74 \%$ to $93 \%$ of these diagnosed cases made one physician visit per year. The annual rate of medically attended GH cases ranged from 261.2 per 100,000 population to 386.6 per 100,000 population.

DISCUSSION: The present report is the first time that administrative data have been used to estimate the annual rate of medically attended $\mathrm{GH}$ cases in Canada. The data include both incident and prevalent cases and are likely an underestimate of the actual number of cases because they only represent diagnosed cases presenting for medical care. Further seroepidemiological and clinical research studies would be helpful to assess the burden of infection and to plan appropriate diagnostic, treatment and preventive counselling services.

Key Words: Burden of HSV infection; Genital herpes; Herpes simplex virus; Physician visits; Rate of diagnosis

\section{L'herpès génital au Canada : décrypter l'épidémie cachée}

INTRODUCTION : L'herpès génital (HG) est la principale cause d'ulcération génitale, mais il n'est pas à déclaration obligatoire au Canada. D’après des recherches menées aux États-Unis, moins de $10 \%$ des personnes séropositives ont déclaré un diagnostic d'HG. Le présent article porte sur le taux de cas d'HG diagnostiqués au Canada entre 2002 et 2007.

MÉTHODOLOGIE : Les chercheurs ont obtenu les données diagnostiques des cas primaires d'HG entre 2002 et 2007 dans l'Index canadien des maladies et traitements, une base de données commerciale qu'exploite Intercontinental Medical Statistics (IMS) Health Canada. Pendant cette période, IMS Health a colligé les carnets de prescriptions propres aux diagnostics auprès d'un échantillon de 652 des 45000 à 49000 médecins en pratique privée du Canada, stratifié selon la région géographique et représentant toutes les grandes spécialités.

RÉSULTATS : Entre 2002 et 2007, on a recensé chaque année de 84398 à 122456 cas d'HG suivis par un médecin au Canada. De 74 \% à $93 \%$ de ces cas diagnostiqués rendaient visite au médecin une fois par année. Le taux annuel de cas d'HG suivis par un médecin oscillait entre 261,2 personnes sur 100000 habitants et 386,6 personnes sur 100000 habitants.

EXPOSÉ : On expose pour la première fois, dans le présent rapport, le recours à des données administratives pour évaluer le taux annuel de cas d'HP suivis par un médecin au Canada. Les données incluent à la fois les cas incidents et prévalents et, selon toute probabilité, elles sous-évaluent le véritable nombre de cas, car elles représentent seulement les cas diagnostiqués qui consultent pour obtenir des soins médicaux. Il serait utile de mener d'autres projets de recherche systématiques, nationaux, séroépidémiologiques et cliniques pour évaluer le fardeau de l'infection et planifier des services diagnostiques, thérapeutiques et préventifs pertinents.
Genital herpes $(\mathrm{GH})$ is the leading cause of genital ulceration $J_{\text {worldwide }}(1,2)$. Although most cases of GH are caused by herpes simplex virus (HSV) type-2 (HSV-2), and most cases of orolabial herpes are caused by HSV type-1 (HSV-1), new diagnoses of GH are increasingly likely to be caused by HSV-1 (3). GH is sexually transmitted and the infection may be primary, latent or recurrent, although most first episodes are not necessarily true primary infections (4). Episodes, including viral shedding, may be accompanied by symptomatic lesions or may remain subclinical. Patient management entails sound clinical examination and laboratory testing such as viral cultures, nucleic acid amplification tests or type-specific serology, antiviral therapy and counselling. $\mathrm{GH}$ is also a cofactor in the acquisition and transmission of other sexually transmitted infections (STIs) and bloodborne pathogens, including HIV (5,6), syphilis (7) and hepatitis $\mathrm{C}$ virus (8). However, $\mathrm{GH}$ is not nationally notifiable in Canada, and there is limited information on its complex epidemiology to guide prevention strategies (9).
There are limited epidemiological data on HSV in Canada. National sentinel surveillance data of street-involved youth in Canada indicate that the prevalence of HSV-1 in street youth 15 to 24 years of age, during 2001 to 2005 , ranged from $57.4 \%$ to $60.6 \%$, and the prevelance of HSV-2 ranged from $14.8 \%$ to $18.6 \%$ (10). Results from national neonatal HSV surveillance, conducted between 2000 and 2003, indicate the annual incidence of neonatal HSV infection in Canada to be 5.9 per 100,000 live births (11). A study with stored sera in Ontario (12) has reported age-standardized seroprevalences of HSV-1 and HSV-2 as $51.1 \%$ and $9.1 \%$, respectively. Approximately $2.3 \%$ of female and $6.1 \%$ of male first-time attendees of an STI clinic in Ontario showed a positive HSV culture during 1980 to 1981 (13), whereas approximately 56\% of attendees at two STI clinics in Alberta were HSV-1-seropositive and approximately 19\% were HSV-2-seropositive during 1994 to 1995 (8). Differential sampling frames and research methodologies make a meaningful comparison of the Canadian data, or the ability to comment on trends in prevalence over time and an increased acquisition of HSV-2

\footnotetext{
${ }^{1}$ Department of Epidemiology and Community Medicine, University of Ottawa; ${ }^{2}$ Public Health Agency of Canada; ${ }^{3}$ Department of Medicine, University of Ottawa, Ottawa; ${ }^{4}$ Dalla Lana School of Public Health, University of Toronto, Toronto, Ontario; ${ }^{5}$ Institut National de Santé Publique du Québec, Montreal, Quebec

Correspondence: Dr Gayatri Jayaraman, Public Health Agency of Canada, 3429-100 Eglantine Driveway, Tunney's Pasture, Ottawa, Ontario K1A 0K9. Telephone 613-941-7539, fax 613-941-9813, e-mail gayatri_joerg@yahoo.ca
} 
TABLE 1

Estimated number of medically attended genital herpes cases per year in Canada (2002 to 2007)*

\begin{tabular}{lcccccc}
\hline & $\mathbf{2 0 0 2}$ & $\mathbf{2 0 0 3}$ & $\mathbf{2 0 0 4}$ & $\mathbf{2 0 0 5}$ & $\mathbf{2 0 0 6}$ & $\mathbf{2 0 0 7}$ \\
\hline Medically attended genital herpes cases, $\mathrm{n}$ & 88,468 & 122,456 & 110,925 & 84,398 & 96,181 & 118,044 \\
Rate per 100,000 population & 282 & 386.6 & 346.7 & 261.2 & 294.6 & 356.2 \\
\hline
\end{tabular}

${ }^{*}$ Extrapolated from the Canadian Disease and Therapeutic Index, Intercontinental Medical Statistics Health Canada

TABLE 2

Number of physician visits per year per unique medically attended genital herpes case (2002 to 2007)*

\begin{tabular}{|c|c|c|c|c|c|c|}
\hline & \multicolumn{6}{|c|}{ Unique cases diagnosed per year } \\
\hline & 2002 & 2003 & 2004 & 2005 & 2006 & 2007 \\
\hline 1 visit & $81,148(91.7)$ & 110,082 (89.9) & $90,761(81.8)$ & $62,502(74.1)$ & $81,994(85.2)$ & $109,994(93.2)$ \\
\hline 2 visits & $2905(3.3)$ & $3651(3.0)$ & $12,701(11.4)$ & $19,430(23.0)$ & $4011(4.2)$ & $6496(5.5)$ \\
\hline 4 visits & $0(0.0)$ & $3742(3.1)$ & $1599(1.4)$ & $0(0.0)$ & $0(0.0)$ & $1553(1.3)$ \\
\hline 5 visits & $1162(1.3)$ & $1539(1.3)$ & $0(0.0)$ & $0(0.0)$ & $0(0.0)$ & $0(0.0)$ \\
\hline 6 visits & $471(0.5)$ & $0(0.0)$ & $0(0.0)$ & $0(0.0)$ & $1342(1.4)$ & $0(0.0)$ \\
\hline 8 visits & $0(0.0)$ & $0(0.0)$ & $0(0.0)$ & $0(0.0)$ & $340(0.4)$ & $0(0.0)$ \\
\hline Total number of cases & $88,468(100)$ & $122,456(100)$ & $110,925(100)$ & $84,398(100)$ & $96,181(100)$ & $118,044(100)$ \\
\hline
\end{tabular}

diagnosed

Data presented as $n$ (\%). *Extrapolated from the Canadian Disease and Therapeutic Index, Intercontinental Medical Statistics Health Canada. The numbers and percentages are estimated and rounded to the nearest approximate

during adulthood difficult. In the absence of baseline pan-Canadian prevalence and incidence data, or morbidity and mortality data, the national burden of genital HSV infections is unexplored, but remains a significant reason for health care consultation and a public health challenge. The present study explored the burden of GH in ambulatory clinical practice and investigated the rates of diagnosed cases of $\mathrm{GH}$ in Canada from 2002 to 2007.

\section{METHODS}

To explore the burden of $\mathrm{GH}$ infection in clinical practice, the present study examined the number of patient visits between 2002 and 2007, from a sample of 652 of the 45,000 to 49,000 office-based physicians in the 10 provinces of Canada, representing 14 major specialties, with a diagnosis of $\mathrm{GH}$ each year. Data on $\mathrm{GH}$ from the Canadian Disease and Therapeutic Index (CDTI), a publicly available database (for a fee) maintained by Intercontinental Medical Statistics (IMS) Health Canada, were analysed. IMS Health is the largest, nongovernmental provider of health information in Canada. The CDTI focuses on physician practices and examines diagnostic trends and treatment patterns. The CDTI database is audited internally for quality control each year. Moreover, IMS Health does not collect any patient identifiers. The physicians participating in the CDTI panel are also not identifiable and sign a consent form with IMS Health before their participation (internal communications with IMS Health Canada). Review of similar IMS Health databases in the United Kingdom has been published (14) and IMS Health data have been used in various studies previously, including studies on antibiotic resistance (15), consultation trends (16), and prescribing trends $(17,18)$.

IMS Health uses International Classification of Diseases, Ninth Revision, Clinical Modification (ICD-9-CM) coding to project diagnosis volume. A five-digit ICD-9-CM code was used as a case definition proxy to extract cases of $\mathrm{GH}$ from CDTI, including subcategories 054.10 (unspecified GH), 054.11 (herpetic vulvovaginitis), 054.12 (herpetic ulceration of vulva), 054.13 (herpetic infection of penis) and 054.19 (other). It did not include other herpes simplex infections such as herpetic whitlow, herpetic viremia, herpes simplex with unspecified, specified or unmentioned complications, or various manifestations of orolabial herpes (internal communications with IMS Health Canada).

IMS Health collects anonymized data periodically using a twostage sampling method, from a sample of 652 of the 45,822 officebased physicians, based on the sampling frame for the year 2003, from across Canada (excluding the Northwest Territories, Nunavut and the Yukon, which are not covered by the CDTI), stratified across five geographic regions and 14 specialties. The CDTI sample design is stable and the panel size of 652 physicians was continuous for the period under study (2002 to 2007), with the number of office-based physicians (universe size) varying from 45,000 to 49,000 . The physicians reported in a diagnosis-specific prescription diary during two consecutive work days per quarter on each medical consultation. IMS Health uses robust statistical tools to derive a matrix of weights layered by region and physician specialty that is adjusted by the number of physician case-reporting days to the reporting period, and the total treatment incidence by diagnosis is computed (internal communications with IMS Health Canada).

IMS Health collects data on how many times a unique case was seen for a specific diagnosis in the past 12 months. Repeat visits of a single patient during the same calendar year for $\mathrm{GH}$ were only counted as a single medically attended case for that year, while also statistically imputing the unspecified number of visits, assuming that the unspecified visits are distributed identically to the specified visits. As a result, the data reported in the present article are marginally more conservative than the data projected by IMS Health.

\section{RESULTS}

The present study estimated the number of medically attended $\mathrm{GH}$ cases in Canada in a calendar year. Between 2002 and 2007, there were 84,398 to 122,456 medically attended cases per year, corresponding to a rate of between 261.2 and 386.6 per 100,000 population per year (Table 1). These data include both incident and prevalent $\mathrm{GH}$ cases, and it was not possible at this stage to differentiate true prevalent cases from true incident cases.

Table 2 presents the breakdown of the number of physician visits per year by each unique case diagnosed. Between 2002 and 2007, the number of unique single-visit $\mathrm{GH}$ cases in a calendar year ranged from 62,502 to 110,082 , with a median of 86,377 .

Figure 1 provides the trends over time for the numbers and proportions of unique single-visit and multivisit GH cases between 2002 and 2007. The data suggest that between $74.1 \%$ and $93.2 \%$ of the unique cases diagnosed with $\mathrm{GH}$ visited their physicians once in 12 months, whereas between $6.8 \%$ and $25.9 \%$ of the unique cases diagnosed with $\mathrm{GH}$ consulted the physician more than once, with a range of two to eight times in a year. 


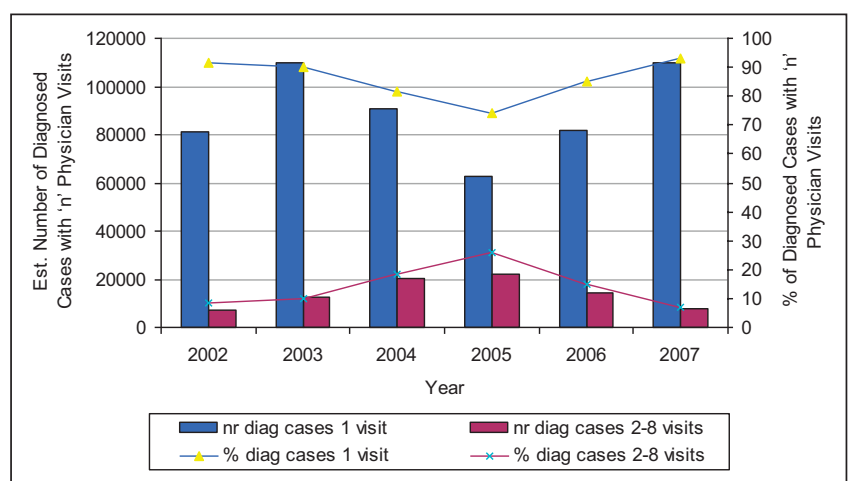

Figure 1) The estimated (Est) number ( $n r)$ and percentage of genital herpes cases diagnosed (diag) with one and two to eight physician visits (2002 to 2007). Extrapolated from the Canadian Disease and Therapeutic Index, Intercontinental Medical Statistics Health Canada

\section{DISCUSSION}

Using physician visits for a $\mathrm{GH}$ diagnosis as proxies, the present study explored the annual numbers and rates of diagnosed cases of $\mathrm{GH}$ in Canada from 2002 to 2007. Physician visits depended on several factors such as severity of infection, individual awareness of signs and symptoms of infection, individual testing behaviour and access to health care services and, as such, do underestimate the burden of infection. The present study found that the number of medically attended $\mathrm{GH}$ cases in Canada in a year ranged from 84,398 to 122,456 , translating to a rate of between 261.2 and 386.6 per 100,000 population. That is, at any given time, between $0.3 \%$ to $0.4 \%$ of the general population in Canada might be seeking treatment for GH. However, this is likely an underestimate of the true burden of this infection because atypical and subclinical infections often go unrecognised or undiagnosed. Fleming et al (19) found that only approximately $9.2 \%$ of all those who were HSV2-seropositive reported a known history of GH. It has been reported that more than $60 \%$ of HSV-2-seropositive persons experience symptoms, but do not associate them with genital HSV infection, approximately $20 \%$ remain asymptomatic and less than $20 \%$ receive a diagnosis of $\mathrm{GH}(20)$. Studies further suggest that asymptomatic infected patients can contribute to the transmission of $\mathrm{GH}$ (21).

The present analysis suggests that between $6.8 \%$ and $25.9 \%$ of the diagnosed cases consulted a physician more than once, with a range of two to eight visits per year. This is consistent with previous research, which also suggests that $\mathrm{GH}$ may reoccur from zero to six or more times a year (22). Generally, all cases of recurrent $\mathrm{GH}$ are due to reactivation of a latent infection rather than to reinfection (23). Genital HSV-1 reoccurs less frequently than genital HSV-2, and its rate decreases further over time (24). Recurrent $\mathrm{GH}$ is frequent in the first year in more than $80 \%$ to $90 \%$ of individuals following primary genital HSV-2 infection, compared with less than $50 \%$ to $55 \%$ of individuals following primary genital HSV-1 infecton (25). Data according to viral subtype or the category of infection were not available in the present study. Further study is needed to differentiate between primary and recurrent $\mathrm{GH}$ infections, (ie, incident and prevalent cases); this could be accomplished through further data mining of CDTI for data for any drug recommended in the prescription diary, because the dosage of antivirals in initial infection is different from the suppressive therapy for recurrent infections.

A comparison with reportable STIs in Canada reveal that there were 73,770 genital chlamydia cases, 11,873 gonorrhea cases and 1206 infectious syphilis cases reported in 2007, versus 118,044 medically attended GH cases in 2007 and an estimated 41,450 incident cases of anogenital warts in 2006 (26-28).

The present study is the first time that administrative data have been used to estimate the rate of medically attended GH in Canada - a preliminary first estimate, notwithstanding data limitations. The present study estimated an annual rate of between 261.2 and 386.6 medically attended GH cases per 100,000 population in Canada for the period between 2002 and 2007, compared with a rate of between 32.5 and 42.7 new diagnoses of GH (at genitourinary medicine clinics) per 100,000 population in the United Kingdom for the period of 2005 to 2007 (29). An extrapolation of the data from CDTI found that there were 84,398 to 122,456 medically attended GH cases in Canada between 2002 and 2007, compared with between 203,000 and 317,000 initial physician visits for $\mathrm{GH}$ reported by the National Disease and Therapeutic Index of the United States for the same period (30).

The present study is not free of limitations. The source database (CDTI) assesses diagnosis volume in office-based practice (physicians); STI clinics, nurse practitioners or other health care providers are not included. The sample size is small and carries the risk of attrition of sentinel practices or selection bias. Granular data were not available for the persent study according to viral subtype, demography (sex, age, ethnicity, location), category of infection (primary, recurrent, nonprimary first episode), diagnostic criteria, or symptom duration and outbreak frequency. The database is unable to directly differentiate between initial or primary and recurrent genital HSV infections, or to differentiate prevalence from incidence rates. Also, the CDTI is unable to inform on the estimated annual health care costs for the GH cases reported.

In view of the atypical, subclinical or unrecognized manifestations of $\mathrm{GH}$, there is often a delay between occurrence of initial symptoms and a patient's visit to a physician and subsequent diagnosis. Typical herpetic lesions may be recognizable during clinical examination, but require confirmation through viral identification techniques such as viral culture, nucleic acid amplification techniques or type-specific serology.

\section{CONCLUSION}

The present study demonstrated that $\mathrm{GH}$ is a major health issue in Canada. Further research, in particular systematic population-based seroepidemiological surveys, longitudinal cohort studies and clinical studies are needed to bridge the knowledge gaps. Without these studies, it is difficult to determine the actual burden of infection, trends over time and to plan appropriate diagnostic, treatment and preventive counselling services.

ACKNOWLEDGEMENTS: The authors thank the Public Health Agency of Canada, which has a contract with IMS Health Canada, for providing access to the Canadian Disease and Therapeutic Index held by IMS. The use of the IMS database in the present study does not indicate endorsement of the company nor responsibility for its products or services.

CONFLICT OF INTEREST/ FINANCIAL DISCLOSURE: MA, RK, GJ, KD, TW - none.

MS has received grants from Glaxosmithkline, Novartis, and Focus for advisory work, honoraria for conferences or reimbursement of travel expenses to congresses.

The views expressed in this article are those of the authors and do not necessarily reflect the views of the affiliated institutions.

\section{REFERENCES}

1. Celum C, Levine R, Weaver M, Wald A. Genital herpes and human immunodeficiency virus: Double trouble.

Bull World Health Organ 2004;82:447-53.

2. World Health Organization. Guidelines for the Management of Sexually Transmitted Infections 2003. Geneva, Switzerland.

3. Scoular A. Using the evidence base in genital herpes: Optimising the use of diagnostic tests and information provision.

Sex Transm Infect 2002;78:160-5.

4. Hensleigh PA, Andrews WW, Brown Z, et al. Genital herpes during pregnancy: Inability to distinguish primary and recurrent infections clinically. Obstet Gynecol 1997;89:891-5. 
5. Wald A, Link K. Risk of human immunodeficiency virus infection in herpes simplex virus type-2-seropositive persons: A meta-analysis. J Infect Dis 2002;185:45-52.

6. Corey L, Wald A, Celum CL, Quinn TC. The effects of herpes simplex virus-2 on HIV-1 acquisition and transmission: A review of two overlapping epidemics. J Acquir Immune Defic Syndr 2004:35:435-45.

7. Cowan FM, Humphrey JH, Ntozini R, et al. Maternal herpes simplex virus type 2 infection, syphilis and risk of intra-partum transmission of HIV-1; results of a case-control study. AIDS 2008;22:193-201.

8. Singh AE, Romanowski B, Wong T, et al. Herpes simplex virus seroprevalence and risk factors in two Canadian sexually transmitted disease clinics. Sex Transm Dis 2005;32:95-100.

9. Steben M, Sacks SL. Genital herpes: The epidemiology and control of a common sexually transmitted disease. Can J Hum Sex $1997 ; 6: 127$

10. Public Health Agency of Canada. Sexually Transmitted Infections in Canadian Street Youth - Findings from Enhanced Surveillance of Canadian Street Youth, 1999-2003. Ottawa: 2006.

11. Kropp RY, Wong T, Cormier L, et al. Neonatal herpes simplex virus infections in Canada: Results of a 3-year national prospective study. Pediatrics 2006;117:1955-62.

12. Howard M, Sellors JW, Jang D, et al. Regional distribution of antibodies to herpes simplex virus type 1 (HSV-1) and HSV-2 in men and women in Ontario, Canada. J Clin Microbiol 2003;41:84-9.

13. Lawee D, Gutman M, Hrytzay M, McLachlin J. Herpes genitalis in patients attending a clinic for sexually transmitted diseases. Can Fam Physician 1983;30:258-64.

14. Wong IC, Murray ML. The potential of UK clinical databases in enhancing paediatric medication research. Br J Clin Pharamcol 2005;59:750-5.

15. Kramarz P, Monnet D, Nicoll A, et al. Use of oseltamivir in 12 European countries between 2002 and 2007 - lack of association with the appearance of oseltamivir-resistant influenza A(H1N1) viruses. Euro Surveill 2009;14:19112.

16. Weisz G, Knaapen L. Diagnosing and treating premenstrual syndrome in five western nations. Soc Sci Med 2009;68:1498-05.

17. Price DB, Honeybourne D, Little P, et al. Community-acquired pneumonia mortality: A potential link to antibiotic prescribing trends in general practice. Respir Med 2004;98:17-24.

18. Campbell NRC, Brant R, Johansen H, et al. Increases in antihypertensive prescriptions and reductions in cardiovascular events in Canada. Hypertension 2009;53:128-134.
19. Fleming DT, McQuillan GM, Johnson RE, et al. Herpes simplex virus type 2 in the United States, 1976 to 1994. N Engl J Med 1997;337:1105-11.

20. Taylor S, Drake S, Pillay D. Genital herpes, "the new paradigm." J Clin Pathol 1999;52:1-4.

21. Wald A, Zeh J, Selke S, et al. Reactivation of genital herpes simplex virus types 2 infection in asymptomatic seropositive persons. N Engl J Med 2000;342:844-50.

22. Goade D. Genital Herpes. In: Cohen J et al. Infectious Diseases, 2nd edn. New York:Mosby, 2004:817-826.

23. Schmidt OW, Fife KH, Corey L. Reinfection is an uncommon occurrence in patients with symptomatic recurrent genital herpes. J Infect Dis 1984;149:645-6.

24. Engelberg R, Carrell D, Krantz E, Corey L, Wald A. Natural history of genital herpes simplex virus type 1 infection. Sex Transm Dis 2003;30:174-7

25. Corey L, Adams HG, Brown ZA, Holmes KK. Genital herpes simplex infections: Clinical manifestations, course, and complications. Ann Intern Med 1983;98:958-72.

26. Public Health Agency of Canada. 2004 Canadian Sexually Transmitted Infections: Surveillance Report. CCDR 2007; Vol 33S1.

27. Public Health Agency of Canada. Brief Report on Sexually Transmitted Infections: 2007. <http://www.phac-aspc.gc.ca/ publicat/2009/sti-its/index-eng.php> (Accessed on March 20, 2010).

28. Kliewer E, Demers A, Elliott L, et al. Twenty year trends (19852004) in the incidence and prevalence of anogenital warts in Manitoba. Cancer Care Manitoba. 2008.

29. Health Protection Agency, U.K. STI Epidemiology in 2009: Rates of new episodes of selected diagnoses per 100,000 population, by gender and age group, 2005-09 Table 5 a (ii). <http://www.hpa.org. uk/web/HPAweb\&HPAwebStandard/ HPAweb_C/1203348026613\#3._STI_Epidemiology_in_2009_ (England) $>$ (Accessed on September 23, 2010)

30. Centers for Disease Control \& Prevention. 2008 Sexually Transmitted Disease Surveillance. Table 43. Selected STDs and complications - Initial visits to physicians' offices, National Disease and Therapeutic Index: United States, 1966-2008. <http://www.cdc. gov/STD/stats08/tables/43.htm> (Accessed on September 23, 2010). 


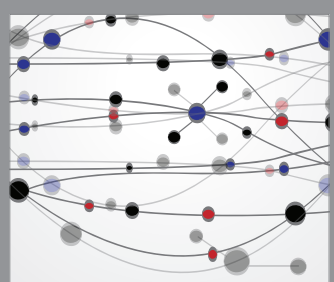

The Scientific World Journal
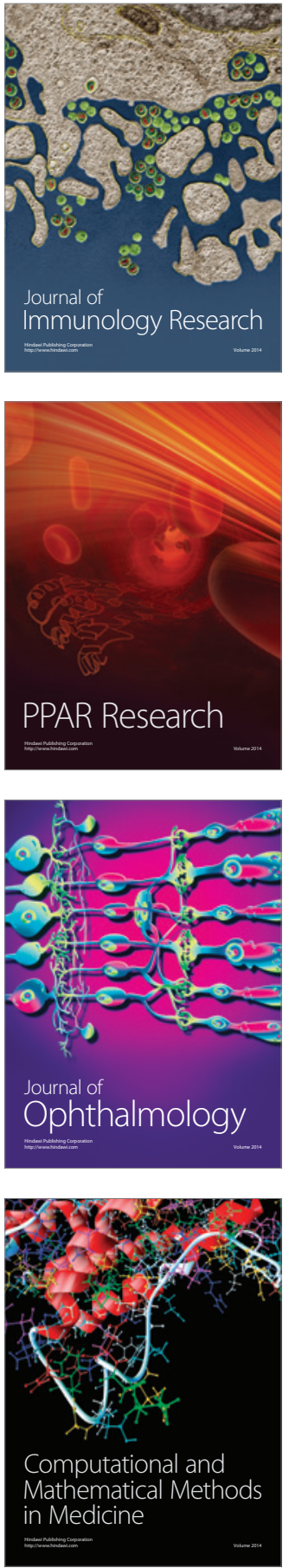

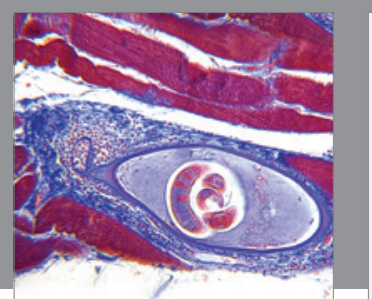

Gastroenterology Research and Practice

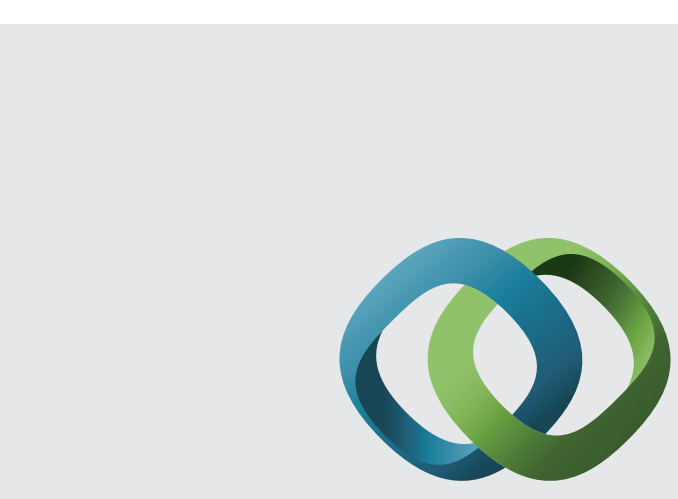

\section{Hindawi}

Submit your manuscripts at

http://www.hindawi.com
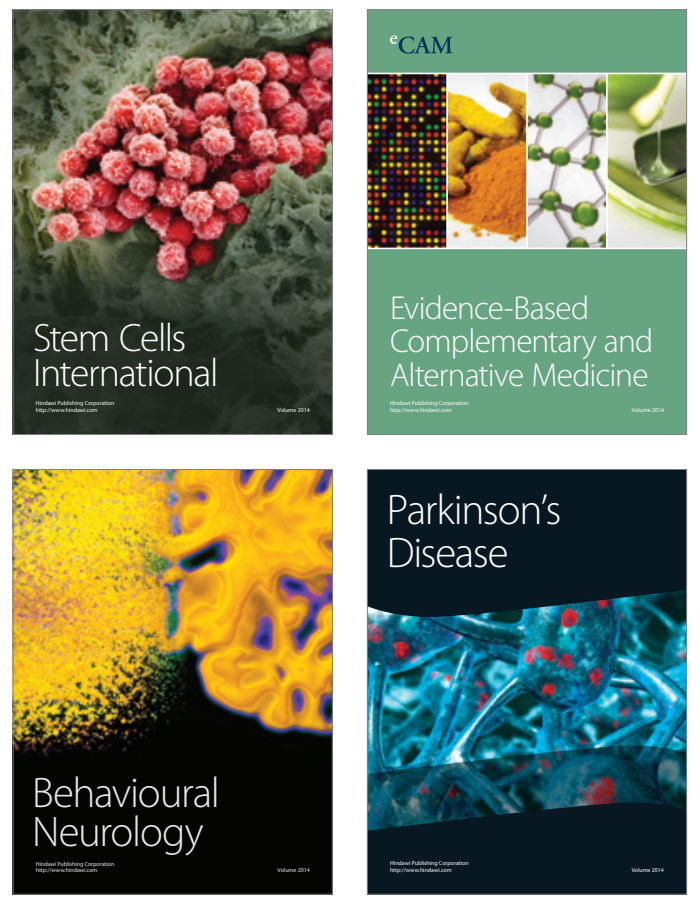
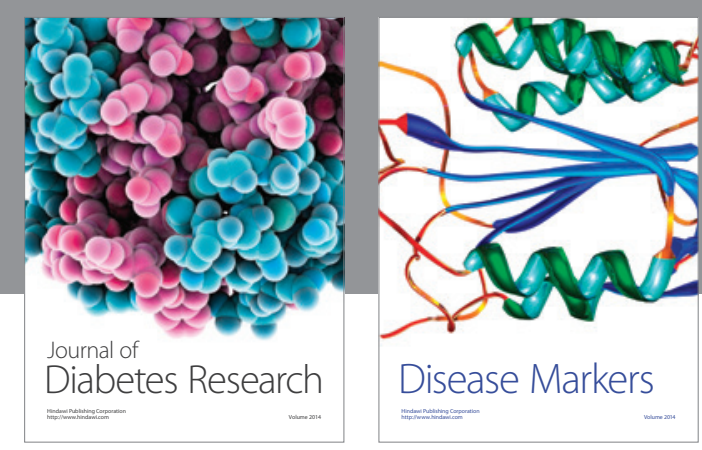

Disease Markers
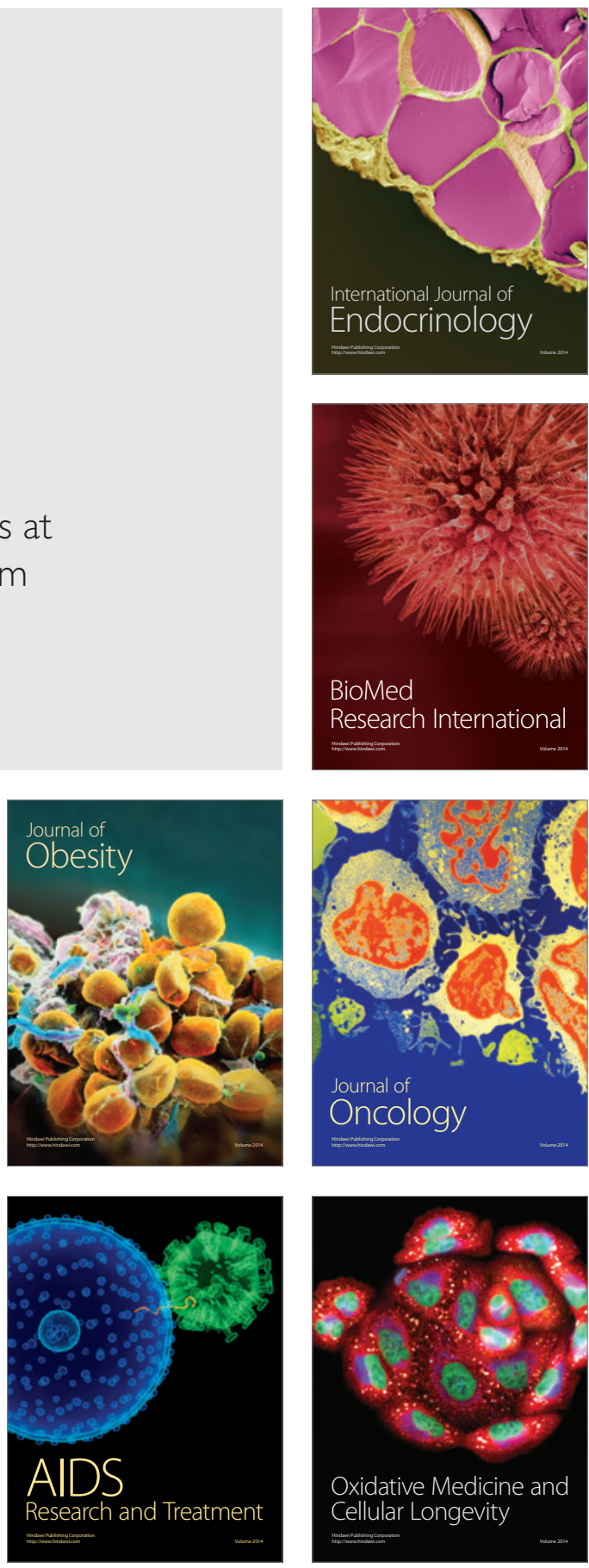